\title{
Actuación en el !nstituto de Literatura en homenaje a Abraham Valdelomar
}

Ei Instihito de Literatura de la Facultad de Letras se sumó a la celebración del $60^{\circ}$ aniversario del nacimiento de Abraham Valdelomar con una actuación que se llevó a cabo en el Salón de Actos. Publicamos a continuación los discursos pronunciados:

DISCURSO DEL DR. MANUET BELTPOY, DIREGTOR DEL INSTITUTO "Jorge PE LITERATURA

Señor Decano:

Señores Catedráticos:

Señores Alumnos:

Señotas, Señores:

Hacen sesenta años nació en la Ciudad de lea, tierra pródiga en vides opimas y en varones ilustres, un varón destinado a ilustrar su patria pequeña y su Patria grande con los frutos de su inteligencia y las gracias de su ingenio. A éste le dotaron las Musas, desde su cuna, con el dón de la poesía, oneroso regalo, privilegio costoso, ministerio de belleza, de verdad y de alegría que se paga y que se ejerce con la vida y con la sangra

Signáronle con el óleo santo de su función de aeda y le dijeron: "Habrás de cantar tu tierra y tu pueblo, la hermosura de sus campos y de sus playas, los trabajos, alegrías y pesares de sus gentes, a fin de 
que su beldad transitoria y su evanescente existir, perduren en el espacio y pervivan en el tiempo para gozo de tus hermanos y de la humanidad. Habrás de cantar también lo que está fuera de tu tierra y más allá de tu grey, pastor de mentes, cantarás la belleza, el placer y el dolor del universo, la mísera y sublime vanidad de la vida humana, que camina por un rumbo sin meta, bajo el sol y bajo las estrellas, a fin de brindarles en tus cantos el pan y el vino que sostengan sus pobres almas abrumadas en su marcha faial y quimérica, y abrillanten los ensueños de sus corazones, bajo la luna. Les enseñarás con tus cantos, como los de tus antepasados orientales, que la vida es una sombra, que la tierra no es más que una senda, por la que ruedan a lo ignoto como hojas verdes y secas los humanos; pero que en esa sombra y esa senda brilla un relámpago, que es el Amor, que no se apaga por virtud de la Poesía; ésta transforma su fulgor súbito en luz y calor perennes, y merced a ellos se guían y confortan los infelices mortales. Ve, pues, Abraham, nuncio nuestro; ye a predicar el Amor, padre de la Poesía, la Poesía hija y sostén del Amor, entre los hombres que nacen y viven por el Amor y la Poesía, pero que no creen en ellos. Ve, hijo nuestro y de nuestro Padre que es el Amor, a predicar el Amor entre las gentes, y a gozar y a sufrir por esta misión sagrada".

Y así empezó su carrera sobre la tierra Abraham Valdelomar, uno de los poetas más puros que ha tenido esta nación y, sin lugar a duda, su mejor artista. No debo ${ }^{y}$ y por eso no quiero - señoras y señores, usurpar el lugar del orador de orden en esta Actuación, con que el Instituto de Literaturáade la Fracultadede Letras/de nuestra Universidad se une al Homenaje que la República rinde a Valdelomar, con ocasión de cumplirse el sexagésimo aniversario de su nacimiento y el vigésimonono de su muerte, para celebrar la memoria, la vida y la obra del hombre de Letras y de Arte, más que del universitario sanmarquino, que lo fué por accidente y muy fugazmente, y que no quiso seguir siéndolo, porque, a decir verdad, la Universidad en aquel tiempo no era precisamente atmósfera para poetas, ni ambiente para artistas y lejos de ser A.lma Mater para ellos solía ser Mater ingratísima.

Sólo quiero decir en breves palabras más que si honramos en esta Casa de las Letras la memoria de Abraham Valdelomar, príncipe de los escritores nuevos del Perú, es en esta virtud y por este magno oficio, que él tuvo y ejerció con toda conciencia y dignidad y sin buscar ni poseer título académico alguno, como la mayoría de sus pares, los grandes creadores literarios, que en su propio genio tienen el diploma y la patente de su magna docencia y no necesitan otro menor, puesto que 
si la Iglesia tiene doctores que nacen tales del vientre de su madre, la Poesía no necesita doctorar a ninguno de sus vates, ya que todos nacen tales del seno de la tierra, madre suya.

Pero si Valdelomar sólo fué alumno de estos Claustros, transitoriamente, movido por su inquietud intelectual; y por su hambre y sed de saber, y si huyó de estas aulas espantado por el obscurantismo cultura! y más que por la deficiente docencia de las disciplinas literarias por la atmósfera iliteraria que aquí se respiraba, en cämbio fué un trabajador y un artífice de las Letras y del Arte Literario, y, como tal, colaboró en la función de esta Facultad, que si no es la de formar poetas y escritores, es por cierto la de edificar la cultura literaria y modelar el gusto del pueblo; renovó la literatura nacional haciendo afluír al humus de nuestro suelc, en él que no quedaban ya sino rastrojos de pasadas cosechas y del cual no surgían sino vegetación anémica, las aguas vivificantes de las corrientes literarias universales y sembrando de nuevo en sus surcos las simientes siemprevivas, pero dormidas en los trojes de la historia y la conciencia nacionales

Porque nuestro Poeta festejado no fué sólo un cantor de la vida y el alma peruanas, un rehabilitador del verdadero nacionalismo literario, decaido y malogrado después de la gran obra peruanista de Palma, que como Palma, aunque en nivel y rumbo distintos, pudo realizar merced a la amalgama de los indispensables y fundamentales ingredientes de toda gran creación årtística: tesustancia ñativa y forma universal, sino que fué además un esteta teórico y práctico, el autor de una nueva estética literaria, concretamente formulada envalgunos de sus libros, artículos y ensayos, que fuera capaz de concebir y formular, más a fuerza de intuición genial que a base de sistemático estudio filosófico, y que justificó y comprobó con sus propias creaciones.

En la historia de nuestra moderna Literatura, si por tal se entiende la que empieza en los comienzos de este Siglo, Valdelomar ocupa el puesto de iniciador, después del gran precursor González Prada, del bri- llante heraldo Chocano y al lado del fino Carrillo y del maravilloso Eguren. Sobre ambos descuella por su trascendencia y por su influjo artístico: aventaja al uno en hondura y al otro en amplitud $y$ a los dos en su dominio múltiple de los géneros literarios. Y se alza como jefe de la pléyade colónida, que definitivamente cierra el desfile de los epígonos del Clasicismo supérstite y del Romanticismo agonizante.

Pero también en los albores de nuestro Novecientos, cuando se apagan los últimos destellos del parnasianismo aristocrático, del simbolis- 
mo hermético y del naturalismo ramplón, esté poeta de monóculo y gardenia, este dandy de club y confitería, este snob de redacción y de garconniere, en cuya rica personalidad artística no había muerto ni sido sepultado el pequeño hijo de lca, el campesino de la tierra de la vid y del dátil ,el niño que jugaba en la playa de San Andrés, con la tortuga y con la "raya", fué el primer "populista" exquisito de nuestra Literatura, el escritor, que, como los Gógol, los Dostoievsky y los Turguéniev, gracias a la admirable aleación de ambos temperamentos en su privilegiado ser de artista, logró hermanar en su obra, todas aquellas escuelas en el modernismo naciente, y uniendo la aristocracia de la forma al popularismo de la esencia, forjan un Arte Literario universal, a fuer de entrañablemente peruano.

DISCURSO DEL DR. EMILIO CHAMPION, CATEDRATICO DE LA

Señor Decano:

Señores Catedráticos:

Señoras y Señores:

Disculpádme si me halláis cohibido yetemeroso al ocupar este sitial. Es la primera vez que en ébme encuentro para decir mi palabra de maestro y esta palabra la he de decir ante mis maestros, siempre respetados y admirados, quienes me enseñaron con su noble ejemplo y su gran sabiduría el cumplimiento del deber. Cumplo, pues, este deber además que como imperativo de mi profesión como imperativo de mi alma, que me orienta hacia todo aquello que es belleza, verdad y poesía. Hoy rendimos homenaje a ese concepto sublime y puro de la expresión más noble de la Humanidad. Porque la Poesía se encuentra en el cenit de todas las ciencias, de todas las artes, de todos los principios y fundamentos, de todas las esperanzas y. de todos los ideales. Es perpetua búsqueda de una verdad en constante gestación y en constante alumbramiento. $Y$ esta poesía, perdonadme la vanidad, se realiza en el cerebro y corazón del hombre en colaboración con la maravillosa naturaleza, que es a su vez realización de la poesía de Dios. Ante ese hombre inclinamos en esta ocasión nuestras frentes y posamos nuestros ojos angustiosos y aplicamos nuestro oído ansioso, para sentirlo nuestro, pa- 
ra recrear como hubiéramos querido crear esa poesía que sin ser de nosotros la sentimos hondamente nuestra, cual semilla que germinara en el espíritu al calor de nuestros amores. Aquel hombre a quien recordamos hoy es Abraham Valdelomar.

Antes permitidme un recuerdo triste. No sería yo, con absoluta seguridad, es lo digo, el que osupara esta ilusire tribuna si otro hombre viviera. Un poeta, un poeta que fué amigo dilecto y que en fuga lírica, la más hermosa de las fuigas, desapareció del mundo que nos rodea, sin fabricar metáforas, desnudo de carnes, sangre y huesos, pues dejó manos y ojos, ropa y maleta parà perderse en no sé que mundo y dejarnos tan sólo su presencia espiritual y poética que no se nos borrará jamás de la retina y su voz cariñosa y burlona que aún nos abriga el corazón. Sabéis de quien estoy hablando: ya he dicho su nombre sin decirlo: Luis Fabio Xammar. El deberia dirijiros la palabra en esta hora. Y al escribir la primera frase de esta semblanza, muy religiosamente solicité su venia para ocuparme de un tema que cautivó sus in quietudes. Disculpádme y os ruego me acompañéis a recordar también hoy a Luis Fabio Xammar.

He dicho que rendimos homenaje a la Poesía. Se me puede preguntar si Abraham Valdelomar fué tan sólo poeta para ocuparme únicamente de este aspecto. Efectivamente Valdelomar incursionó en todos los géneros: verso, cuento, novela, teatro, crítica, periodismo llegando hasta manejar la pluma para hacer caricatura. adNo nos recuerda su posición a la de ese poeta amado y recordado de la España de otrora que se llamara Federico García Lorca? Tambien García Lorca fué polifacético en el Arte: poeta, dramaturgo, músico y actor . Valdelomar pudo situarse en todos los campos de la Literatura, ejerció en todos los góneros. Toda su obra está impregnada de esa belleza a que me refiero y por eso he llamado a esta hora, hora de tributo a la Poesía. Cuanto hizo y cuanto pensć Valdelomar fué poesía. Su mano y su pensamiento tan sólo dejaba huella de la belleza. Poseía un sentido agudo del arte y sufría cuando las obras carecían de las cualidades estéticas. Su prosa y su verso están colmados de belleza; su cuento y su drama; su nota periodística y su carta amical; su palabra hogareña y su palabra paleconcertina. Buscaba la belleza por doquier como algo ignorado, mas presentido, que se sabe que existe pero que no siempre se encuentra en su plenitud, como esas verdades dogmáticas que no se pueden probar pero que por la fe se aceptan y consuelan. Su vida fué ese caminar constante sin llegar por el camino infinito del artista, buscando la poesía que emana de las formas, sean cuales fueran, 
en ese afán de encontrar la cima sin hallarla nunca, como el alma cuando busca a Dios y tan sólo lo encuentra después de la muerte. Abraham Valdelomar es por eso poeta por excelencia y digo poesía al hablar de su obra completa, porque jamás se salió de esa disciplina estética que cumplió con la severidad de un religioso y con la idolatría de un fanático.

He deseado tener mayor tiempo para estudiar esta personalidad que puede ocupar muchas pácjinas pero las horas son estrechas para hacerlo y por eso os ofrezco esta ligera semblanza conmemorativa, que es elogio si queréis, flor de recuerdo ante la fecha de un calendario y nada más que admiración a la obra fecunda de Abraham Valdelomar que ha añadido laureles a la literatura de nuesira querida Patria.

\section{VALDELOMAR JEFE DE UNA INSURRECCION}

José Carlos Mariátegui lo denuncia así. Aceptamos esta grave acusación. No llegó a consumarse la revolución, nos dice, pero luego la intentó. Un buen día ese grupo de escritores, artistas y pensadores que forman la generación de fin de siglo, acordaron pregonar a todos los vientos sus ideas y sus ideales y lanzaron sin reunión previa' su protesta contra los valores académicos, torcieron el cauce del caudaloso río y viajaron contra la corriente. Es el movimiento Colónida del que fué capitán muy ilustre Abraham Valdelomar. Dieron paso a las nuevas formas, deritro de lajadmiración, a la inteligencia. No era tiempo para considerar tan solo con valor lo tradicional,- lo que acreditaba la tarjeta de la cátedra" yolág respuestalali apellidorilustre que obligaba a ser inteligente. Los moldes venidos de la vieja Europa seguían en vigencia y en ellos depositaban sus indudables talentos los hombres que seguían pensando como pensaron sus antecesores. La Universidad, nuestra vieja y querida Universidad de San Marcos fué duramente castigada y menospreciada por los insubordinados que capitaneara Valdelomar. Y, oh paradoja, hoy elevamos en la cátedra nuestra palabra de admiración a la figura que representa esa lucha. De labios de maestros que fueron condiscípulos de Valdelomar hemos escuchado la razón por la cual se declaró enemigo de la Universidad. Y la razón es razonable. Nosotros tampoco querríamos una Universidad en donde la única voz, sin eco y gastada fuera la del maestro; que no era maestro porque no escuchaba; que no era maestro porque no enseñaba, que no era maestro porque no se renovaba, que no era maestro porque no conmprendía a la juventud, pues consideraba que existía una distancia insalvable entre la carpeta del alumno y el pupitre del profesor. Ese abismo ha desa- 
parecido tiempo ha felizmente. Contra esos hombres y no contra la majestad de la Universidad-se levantaba esa juventud iconoclasta, justamente iconoclasta. Talentos como los de Valdelomar, César Atahualpa Rodríguez, José María Eguren, Enrique Bustamante y Ballivián, Leonidas Yerovi y tantos más, tendrían que asistir a las clases, si alguna vez se tomaron la molestia de asistir, con una sonrisa en los labios, con aire de suficiencia y desprecio y dedicaron su tiempo a enseñarse así mismos. porque ellos eran fuentes de sabiduría y la palabra de la cátedra se encontraba muy por debajo de sus conocimientos y de sus inquietudes. La generación de Valdelomar es autodidacta por ese motivo. No tuvieron maestros. Salvo unas raras excepciones de hombres que se entregaron a la Universidad y conservaron el prestigio de los claustros sanmarquinos, sería larga la lista de los que no necesitaron de los títulos académicos.

En un día 27 de abril de 1888, en la cercana ciudad de lca, nace Abraham Valdelomar. lca es un territorio que nos recuerda al paisaje árabe: tiene ambiente de desierto: sol ardiente, arenas desoladas, árboles solitarios y añosos y se encuentra de trecho en trecho pequeños oasis. Sólo faltan los camellos lentos y los beduinos sensuales atravesando las inmensas llanuras. Hasta sus habitantes tienen la piel de aceituna y el espíritu melancólico del moro. Por confesiones del mismo Valdelomar parece que su hogar sin ser pobre no gozaba de la opulencia " pero sí de la lelicidáde CDesde niño, el mar le ofrece su regazo: vive desde muy tierno en Pisco, población que encontrándose muy cerca de lca, sin embargo es muy distinta. El paisaje se torna aquí: hay pescadores, botes, -olas, playas, puestas de sol, alegrías de las gentes marineras y conversadoras, temores de naufragios, llegadas de barcos, movimiento de vida y ansias de salir por esa puerta inmensa que es el océano y que invita día a día al viaje y a la aventura. Siempre llevó una vida campestre: nos habla con verdadero deleite de sus excursiones a las huertas iqueñas acompañado de sus varios hermanos, con quienes se sube a los árboles, para saborear las rojas ciruelas, las cerezas suaves y los mangos olorosos, las uvas melosas y los melocones maduros. Es seguramente la etapa más feliz del poeta, en que contempla embelesado los oasis de su tierra iqueña, la pureza de los niños inquietos y la bondad de la tierra ubérrima. Cuando viaja hacia la costa iel mar lo vuelve triste; con esa amorosa tristeza del que va a engendrar belleza: 
Mi infancia que fué dulce, serena, triste y sola se deslizó en la paz de una aldea lejana, entre el manso rumor con que muere una ola $y$ el tañer doloroso de una vieja campana.

Dábame el mar la nota de su melancolía, el cielo la serena quietud de su belleza, los besos de mi madre una dulce alegría y la muerte del sol una vaga tristeza.

En la mañana azul, al despertar, sentía el canto de las olas como una melodía y luego el soplo denso, perfumado del mar,

y lo que él me dijera aún en mi alma persiste; mi padre era callado y mi madre era triste y la alegría nadie me la supo enseñar.

No puede escribirse mejor biografía de la niñez de Abraham. Valdelomar que la que él ha escrito en ese maravilloso soneto: allí está su alma, su vida, lo que él hubiera querido que fuera su vida, detenerla para gozar de su aldea lejana, del manso rumor de su ola, del tañer de su vieja campana, del sol que muere, de la melodía del mar, de la mudez de su padre y la tristeza de su madre, que qanto le enseñaron y tan honda huella dejara en-Sul alma siemprentriste de peregrino poeta.

Más tarde tendrá que viajar a Lima. Y será alumno del Colegio Nacional de Guadalupe. Será guadalupano; es bastante decir. Su inquietud encuentra la atmósfera propicia para desplegarse. En este centenario colegio caben todos los principios, todas las ideas y todos los gustos. Allí se encuentra el alumno estudioso y disciplinado, el ocioso y badulaque, el católico ferviente y el anárquico descreído; el hijo del rico y el hijo del pobre; el niño que más tarde ocupará alto puesto en la administración pública, en las profesiones liberales y el que se ocupará de modestos menesteres; el poeta y el músico; el obrero y el empleado; el industrial y el profesional y en fin todos los hombres que formarán nuestra nacionalidad en abigarrado pero armónico consorcio. Guadalupe se siente orgulloso de haber tenido en sus aulas a un alumno quizá indisciplinado, incumplido, pero que dará lustre al ya ilustre pri- 
mer Colegio del Perú. "La Idea Guadalupana" es el periodiquito que dirigirá juntamente con Manuel A. Bedoya. Terminada su instrucción secundaria ćl mismo no sabe la carrera que desea seguir, mejor dicho la sabe, pero seguramente considera que el medio le obliga a tener un título profesional, el medio y sus buenos padres que ambicionan lo mejor para su hijo inteligente. Intenta ingresar a la Escuela de Ingenieros y a la Facultad de Letras de la Universidad de San Marcos. La política agita a los espíritus y Valdelomar no se escapa de esa agitación. Lo vemos en los claustros sanmarquinos listo a ocupar el lugar de mando que no logra conquistar. Funda una agrupación billinghurista de universitarios y como caballero cruzado de su credo se bate en duelo con quien iba a ser más tarde su grande amigo Alberto Ulloa. Logra más tarde un cargo diplomático en Europa y cumple el anhelo de todo artista: conocer el viejo mundo. No pierde el tiempo en sus viajes, especialmente por Italia, donde recoge su pensamiento y su cuitura. De nuevo lo tenemos en la Patria con el bagaje formidable de sus conocimientos que infundirá en su futura obra literaria a través de sus ojos sabios y de su imaginación poderosa. Su producción se torna múltiple: periodismo, conferencias, cuentos, poesía, teatro y crítica brotan inagotablemente de su talento prodigioso. Desgraciadamente su joven vida se trunca. En el mes de noviembre de 1919, muere trágicamente el este. ta, el exigente y pulcro gue nos diera junto con La Verdolaga, fina especulación de belleza,bla psícologia del gallinazo, Srofunda y mordaz sátira del espíritu criolloge Puccinelli Converso»

\section{CRIOLLISMO EN VALDELOMAR}

¿Qué entendemos por Literatura criolla o criollista? Creo yo que ha de ser la producida por criollos y en ambiente' criollo. Es decir es el producto del sentimiento criollo, amor por lo criollo, conocimiento de su ambiente y de sus raíces y expresión psicológica y artística de sus elementos. Por eso es auténticamente criollo Manuel Ascensio Segura, y lo es auténticamente criollo Caviedes, y lo son tantos otros que pregonaron su criollismo amorosamente, sin fabricar fuera de su espíritu palabras y pensamientos, sin espontaneidad ni cariño. Por eso es auténticamente criollo el hombre de nuestro pueblo, ingenioso en el chiste, refranero, liso y burlón. Si la Literatura Criolla es el resultado de ese ambiente, expresado por la palabra galana y el ingenio vivaz de un artista tendremos un arte criollo. Abraham Valdelomar posee esa palabra galana y esa chispa de ingenio y expresa con claridad y amor 
ese sentimiento que recibimos y deseamos. Por consiguiente su obra literaria será criolla. Los cuadros que nos pinta en sus cuentos nacionales, bien es verdad que puede ser el cuadro hogareño de todos los hogares del mundo, con los hermanos y hermanas, con la llegada del hermano que trae obsequios para los familiares, pero el detalle es diferente, lo singular es singular: lo que el hermano trae sólo lo puede traer un hermano del Perú "Quesos frescos y blancos, envueltos por la cintura con paja de cebada, de la Quebrada de Humay; chancacas hechas con cocos, nueces, maní y almendras; frijoles colados, en sus redondas calabacitas pintadas encima con un rectángulo del propio dulce, que indicaba la tapa de Chincha Baja; biscochuelos en sus cajas de papel, de yema de huevo y harina de papas, leves, esponjosos, amarillos y dulces; santitos de piedra de Guamanga tallados en la feria serrana; cajas de manjarblanco, tejas rellenas y una traba de gallo con los colores blanco y rojo" Aquí tenemos al caballero Carmelo el más glorioso personaje de los cuentos de Valdelomar. Y esa casona donde reciben al padre sólo puede estar en el Perú. $Y$ sus Ebaristos el sin $\mathrm{H}$ y el con H. son asimismo personajes de nuestro medio, con la doble personalidad que resalta Pirandello, pero a esos sujetos - árboles, sujetos - piedras los hemos visto en nuestros pueblos, amando silenciosamente, con una rica vida interior, viviendo su vida sin importancia al otro lado de un mostrador en el silencio de las tardes aburridas y eternas noches de la aldea. Nos presenta Valdelomar la aldea, cercana al puerto y arrullada por el mar, con la charla de los pescadores y el movimiento de las bajfas. ulesín nosi decribeesuoniñez en Pisco al lado de su padre que "tenía la faz tranquila, brillante mirada, bigote pródigo" y "un hermoso tipo moreno", hombre más pegado al mar no podía darse. Y su madre era una mujer buena de alma sensible que lloraba cada vez que se ausentaba el padre del hogar. Tiene un cuento de tema incaico "Chaymanta Huayñu"." que incidentalmente nos lleva al paisaje serrano. Pero me parece que no siente el paisaje como motivo, prima en ese cuento su acento trágico y en casi todo su relato hace intervenir al río que es agua al fin y que lleva al lugar que tanto lo impresionó: la orilla del mar, como lo hace notar Xammar. Al leer las páginas de la obra de Valdelomar nos acercamos tanto a nuestras tierras costeñas que nos prepara para leer las páginas desgarradas de César Vallejo y nos recuerda las horas gratas que nos brindaron las páginas de las tradiciones de Ricardo Palma. 


\section{VALDELOMAR EL TRAGICO}

La belleza que nos brinda la obra literaria de Abraham Valdelomar nos deja una huella de tragedia. Creo que hubiera sido el mejor dramaturgo de nuestra Patria. Recordemos que murió muy joven. Esa tragedia nos la presenta én los escenarios de su múltiple obra. Sus personajes tienen una riqueza espiritual que desborda en argumentos orales, aunque estén enfermos, aunque se encuentren en las puertas de la muerte, jamás se presentan míseros de ideas, son personajes de mucho monólogo interior y que justifican su presencia en el argumento de la obra. En Yerba Santa, novela escrita a los dieciseis años, en su triste y dolorosa niñez, inquieta y pensativa, como él mismo confiesa, nos presenta al taciturno Manuel , quizás alma de si mismo, quien canta melancólicamente:
No volvió. nunca mi jamás su mano volví a besar; todas las tardes moría el sol y su ventana no se abrió más.... y su ventana no se abrió más.

El niño Abraham sueña que el protagonista, amante decepcionado, como son todos los amantes adolescentes, cabalgasen brioso corcel hacia un mundo en brumas para perderse en el misterio de los sueños. Quiere que muera el protagonista porque su pena por" los amores truncados sólo se resuelve tras de la ventana que nuca se abre; la tumba. Asimismo en "Ia Ciudad de los Tísicos" todo se confabula para asustar al lector, pero a la vez es un recreo para el pensamiento las agudas divagaciones sobre arte, desfilan enfermos que son actores geniales, grupo de hombres y mujeres fracasados físicamente pero alegres, anhelantes de vivir y de, estrecharse en el abrazo vital de hombre y mujer. No son los fracasados de un Lenormand, física y espiritualmente, que marchan en declive, estos fracasados irónicamente marchan alegres, buscando y saboreando un poco de felicidadi a la que tienen derecho, sin importarles sus pulmones son carcomidos por el bacilo de Koch. Sin hacer caso de la fiebre cada cual urde su novela hermosa, rociada con champán. Son enfermos perfectos, amables y hasta envidiables. Abel Rossell, autor de la correspondencia traviesamente hace romántico el escenario de un sanatorio cualquier, donde un tuberculoso cualquier escribe versos que no puede escribir un cualquier. 
Trágica es su concepción del arte. Alguien ha dicho que la base donde reposan sus principios estéticos no tienen la solidez de las disciplinas filosóficas. Seguramente es lo cierto. Pero en cambio tiene la solidez de sus originales ideas. Juega primero aquí y allá con ideas y palabras para luego deducir sus geniales apreciaciones, como lo comprobamos en Belmonte el Trágico, donde vemos más que un estudio de Belmonte mismo, un eloglo del Toreo y de España. En sus cuentos notamos también esa íntima tragedia de sus personajes. El Caballero Carmelo termina su vida "acercándose a la ventana, mirando la luz, agitando débilmente las alas de oro, ensoñoréase y canta, retrocede unos pasos, inclina el tornasolado cuello sobre el pecho, tiembla y se desploma, estirando sus débiles patitas escamosas y mirando a los suyos amorosamente, expira". Todos lloran la muerte del héroe. En el vuelo de los cóndores, Miss Orquídea, la bellísima trapecista fracasa en su difícil prueba y la vemos retirarse del escenario en una silla de ruedas. El fin de Ebaristo, mejor el fin de los Ebaristos, no puede ser más trágico, sus vidas se unen para siempre pero con el lazo de la muerte, sin un momento de felicidad sino más bien con últimos momentos de burla y engaño de los hombres. Y la Señora Blanca de los Ojos de Judas, muere entre las olas del mar y del Manuel de Yerba Santa, ya hemos recordado su muerte. Así presenta a sus mejores personajes: envueltos en tragedia, pero hermosos, con llama interior, colmados de anhelos y de impulsos, cantando durante su muerte bellísimas saetas.

\section{FINAL}

\section{"Jorge Puccinelli Converso»}

Tenemos el compromiso de ocuparnos más detenidamente de la obra literaria de Abraham Valdelomar. Sería interesante estudiar cada aspecto y cada género que cultivó. Quizá lo logremos en el mes de noviembre próximo al recordar el aniversario de su prematura muerte.

Válgame decir, ahora, que Abraham Valdelomar junto con la pléyade de Colónida marca en la Historia Literaria del Perú un hermoso plinto donde reposará un arte esencialmente peruano. Momento criollísimo de una interesante bohemia última. No creemos que influyera en los escritores posteriores porque aún los mismos escritores colónidas eran distintos. Junto a una poesía transcendeatal de José María Eguren, meditativa, solitaria, sin ubicación geográfica, crece la poesía de José Santos Chocano, con riqueza de palabras, fácil al entendimiento de las multitudes, con tendencia a lo popular. Eguren es la poesía opuesta 
a la de Chocano siendo los dos grandes poetas y aprovecho la oportunidad para recordar la necesidad de reinvidicar la obra poética de Chocano, un poco olvidada.

El Instituto de Literatura de la Facultad de Letras de la Universidad Nacional Mayor de San Marcos al recordar a Abraham Valdelomar recuerda legítimamente a uno de los suyos. Fué un trabajador infatigable, un verdadero obrero de la Literatura; un profesional dedicado única y exclusivamente a sus tareas. Periódicos y Revistas de la época son las pruebas de su agotador trabajo. No ha dejado muchos libros pero sí una copiosísima obra. Por ser un trabajador incansable, un creador genial, un peruano amantísimo de su Patria, le rendimos tributo. Por su palabra y por sus hechos lo admiramos y lo consideramos un maestro en esta casa del estudio.

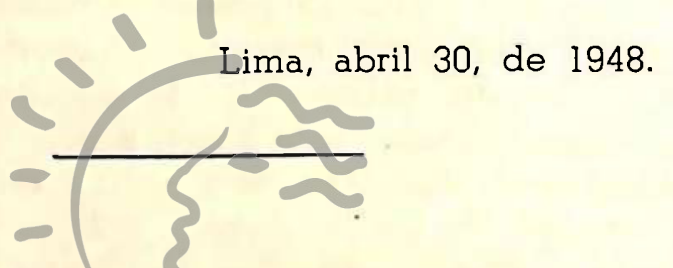

DISCURSO DEL ALUMNO SR. ARTURO SALAZAR LARRAIN

Señor Decano de la Facultad de Letras,

Señores Catedráticos lioteca de Letras

Señores:

Toca hoy - en esta oportunidad a la Facultad de Letras de la Universidad Nacional Mayor de San Marcos - hacer memoria de Abraham Valdelomar en esta efemérides del $60^{\circ}$ aniversario de su nacimiento.

Al discurrir en este aniversario - pasados ya los 28 años de su muerte - queremos hacer presente nuestra voz, para ceñirla al reconocimiento de su vida y de su obra, aún cuando se corra en este intento el albur de alguna generalización harto sabida.

No nos conduce a esta tarea el afán de la hipérbole ni el intento juvenil de consabida iconoclastia. Al hablar de Valdelomar tan solo nos ha de dirigir la firme convicción de su tributo y la entrañable brillantez de su perfil; la huella honda de su dibujo humano, de su semblanza y de su trazo interno. Porque es preciso saberlo: Valdelomar hombre y persona, otea siempre por cima de su obra transparentando en la tretuda nitidez de su contorno personal, aquella su actitud porfiada, intisfecha, humana y libre. 
Actitud esta que - a través de innumerables sinsabores - se concreta y se plasma en una recia personalidad, que sostiene después tercamente contra un medio en el que campeaba el prejuicio y la mediocridad unidos a la pacatería estacionaria de una tradición - por qué no decirlo - de extrema mojigatería.

Buscador de sí mismo, infatigable, Abraham Valdelomar se ofrece - dentro del campo literario del Perú - en sus múltiples posibilidades de novelista, poeta, periodista y escritor teatral.

Dueño de una exquisita sensibilidad, se ensaya en innumerables intentos de plasmación artística, que ocupan así los nueve últimos años de su existencia.

Valdelomar es ante todo un insatisfecho en perenne gesto de inquietud; un solitario que gusta de rodearse a sí mismo muchas veces:

"Ya en mi intancia - dice_ con mi madre y mis hermanos, formábamos unidos un grupo contra el destino, y para defendernos de él nos abrazábamos más estrechamente".

Este recogimiento íntimo pleno de medrosidad ante el destino, ante lo exterior de sí mismos, es lo que maduraría más tarde en el gesto ¡tan aparentel de desdén con que miraba lo demás. Este gesto de retraimiento, este ademán - que por otra parte es índice cabal de su sensibilidad - era involuntario si se tiene en cuenta que obedecía en él como acto reflejo casi inconsciente: Ademán que luego iría endureciéndose y haciéndose carne con su propia persona y con su propia personalidad.

Este volcarse a sí mismo sería el único reto, el único desafío, que pudo oponer al medio de su éfoca, agresivo ye afentante.

Por salir fuera de su angustia, por evadirla momentáneamente: es que adopta aquella POSE WILDEANA con que tanto se le ha motejado: que para ello sólc se reclama una vida como la de Valdelomar con un ingenio parecido también al de Valdelomar.

Toda esta angustia, toda esta tristeza - tristeza de lo íntimo suyono lo conducen a la desesperación, tan sólo lo inducen irremisiblemente al refugio de una pose que se nos antoja interesante porque advertimos ya en ella, toda la trastienda de un mundo de justicia reprimida.

A esta POSE aúnaba el ingenio de su humor; aquel humor del que nos hablaría José Carlos Mariátegui en su ensayo sobre éste. Humor que se adivina hasta en el gesto más insignificante de su vida. Con él Abraham Valdelomar dió su respuesta, la única respuesta que pudo dar, entonces, y que trasunta ya, todo el significado de una vida de lucha contra un medio adverso. 
El nueve de febrero de 1918, escribía con aquel humor que tantos enemigos le hubo de ganar:

"Yo era hace unos días, redactor de un diario. Este diario indemnizaba con la mezquina y despreciable suma de veinticinco libras, el malestar pesante que me ocasionaba ir al periódico de vez en cuando. Yo creía que mi visita hebdomadaria al periódico y un aríículo brillante de tarde en tarde, eran bastante retribución de parte mía por las veinticinco libras; además yo a veces solía decir: "buenas tardes compañeros" aunque las veces que tuve esta clase de generosidades, no se me aumentó el sueldo".

Este episodio retrata fielmente el espíritu que le animaba; espíritu de rebeldía que le lleva irremediablemente hacia el ademán pedante - hacia el gesto de sedicente orgullo:

"Soy orgulloso y soy rebelde - decía - porque soy sincero y soy libre. Soy orgulloso y creo que el orgullo es una noble virtud; soy rebelde porque creo que la rebeldía en un ambiente pervertido y mediocre como el del Perú, es una recomendación y un título".

He aquí ligeramente esbozada su propia definición y su propia justificación.

Valdelomar adquiere y cuaja sólidamente su personalidad a fuer de innumerables escarceos; personalidad sentada a base quizá de sufrimientos, y superada por cima de sus habituales "personalismos"; personalidad que engendra tales personalismos sin supeditarse a ellos. Personalidad que traduce un modo de comportarse- difrenciante de lo demás, al que añader Ia secuenciacin ell pourito despersonalizarlo todo.

"Personalismo y personalidad son cifras en la ecuación humana de Valdelomar" ha dicho el profesor Fabio Xammar en su trabajo sobre éste.

La escritora peruana Evangelina, ante la dualidad manifiesta - en Valdelomar - de su obra y de su vida, se asombraba de no ver re. tratada ésta en aquella. "Es curioso - dice - notar como contrasta la sinceridad literaria de Valdelomar con la ficción de su vida, su amaneramiento un tanto teatral y representativo en determinadas ocasiones; enteramente en oposición a la franqueza absoluta de sus escritos, en los que aparece en ciertas ocasiones mostrando su alma saturada de belleza en una confesión en donde el candor y la beatitud se anidan".

Sorpresa un tanto improvisada y espontánea, por cuanto, es bastante sabido que las condiciones psíquicas del creador de una obra, es decir, sus habituales modos de conducta en la vida, no se vacían o se 
traducen íntegramente en la obra. Esta guarda respecto de los rasgos psíquicos de su autor, sinó una absoluta independencia la menos sí una formal y definida autonomía.

Es harto sabido, por otro lado, que gran parte de los rasgos de una obra proceden o son extraídos del campo de la experiencia colidiana; iasgos que se dan a través de su autor y que son trasmitidos a la obra por el intermedio de su factor creativo; Factor, demostradamente irracional y por ende inderivable (directamente) de los modos personales de conducia observados por su autor.

No es raro pues que en Valdelomar se den estos dos modos tan diferentes y alejados entre sí: por un lado una vida de afectación y por otro, una obra de sencillez prístina y elocuente.

Es cierto que Valdelomar optó este medio de vida y que efectivamente llegó a extremos desorbitados; pero a la vez es tanto mas cierto que ello lo hizo impelido por los designios de una ley inexorable trazada de antemano. El artista, es decir el hombre creador, se siente al situarse en el mundo, como desposeído de todas las prebendas terrenales; se vé y se siente huérfano de tales satisfacciones, quizá si porque ellas en último término, constituyen algo así como un "esta. do peligroso" que puede atentar negativamente, en desmedro de su facultad de creador.

El Universo, la humanidad, parece como que se empeñaran en hacerle cada vez más desgraciado, tal vez si porque con ello se fomenta automáticamente la formación de un egoismo fatal y necesario que incube, por cierto, los "elementos energéticos primarios, que exige su creación artística.

En Valdelomar se dan dos direciones, dos sentidos opuestos diametralmente: por un lado se nos muestra retorcido, subjetivo, personalista extremoso, aristócrata si se quiere del más subido tono; por otra parte, pleno de inquietud igualitaria; inquietud que mana ciertamente del requerimiento natural de su conducta, amplia de fé en un destino humano superior.

El Poeta, en general el artista, no se dá en la realidad aislado o abstraído de ella: nó. En esta se comporta en su doble papel de receptor y donante. El Poeta se nutre ávidamente de la realidad, consume gran parte de ella para después donarla y ofrecerla al través de su tamiz de artista.

La Poesía para ser poesía plenamente, es necesario que esté identificada íntegramente con el linde tremante de su humanidad. Es por consiguiente absurdo explicarla derivándola exclusivamente de factores 
personales fretendidamente condicionantes. Poesía es zumo de humanidad.

A Valdeiomar le venios llegar por esta vía hasta el terreno de lo social, uncido de la mayor convicción y ciel más tierno respeto. Ya Mzriátegui nos dá cuerita de ello en su ensayo sobre Valdelomar :

"Recuerdo - dice-. que én nuestros últimos coloquios, escuchaba con interés y con reseplo mis primeras divagaciones socialistas. En es te instante de gravidez, de maduración, de tensión máximas, lo abatió la muerte".

A.brahain Valdelomar se vuelca en la acción, lleva a la praxis el summun de sus convicciones políticas; aún cuando es sólo en los últimos años, cuando advertimos en él, aquel proceso de identificación con las corrientes ideológicas que exigían la justicia social y económica por encima de privilegios de clases y castas:

"Invocamos vuestro apoyo y vuestra piedad - decía en alguna de sus conferencias - en favor de la raza esclavizada, envilecida, ignorante, bestializada, por la cruel y vergonzosa rapacidad del gamonal, primer enemigo de la democracia y de la libertad".

Su visión política lo condujo a la comprensión única del problema social local, sin poder dejarle preveer claramente, entonces, el peligro que significaba la presencia de aquel sistema poderoso que atentaba abiertamente contra la libertad económica - vale decir total - de las pequeñas nacioneß de nuestro hemisferiō.

Abraham Valdelomar supo llevar este aliento de justicia popular

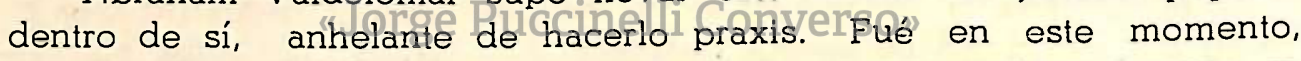
en esta circunstancia, cuando lo abatió la muerte accidentalmente en la ciudad de Ayacucho el año de 1919.

Bien se podría intuir en Valdelomar esta inquietud de justicia social y eccnómica, este derramarse en la realidad y absorberla, este identificarse con el anhelo de reivindicación comunitaria, por cima de los intereses preponderantemente económicos de los grupos oligárquicos y clasistas. En este aspecto de vida, Valdelomar olvidaba ése su individualismo aristocrático para allegarse, complaciente y gustoso, hasta las gentes sencillas y humildes.

Ello fué también su obra: buscar siempre en sus cuentos, la expresión de lo humilde, de lo sencillo, por el medio de sus narraciones ajustadas, precisas y elocuentes.

Llenos de esmerc sus cuentos, delatan en la forma literaria la evocación de una vida pletórica de belleza aldeana, primitiva, sencilla, intensa y noble. Y es a través de ellos - sus cuentos - en los que Val- 
delomar deslinda su preferencia; a través de ellos es que descubrimos el paisaje sincero y elocuente de su pueblo, de aquella aldea en que "las palmeras se multiplican y las higueras dan sombra a los hogares, tan plácida y fresca, que parece que no fueran malditas del buen Dios, o que su maldición hubiera caducado".

Es el paisaje de la Costa Peruana dado a través de un lenguaje de armonía fonética y sintáxis adecuadas, que permiten la visión de un paisaje de ritmo perezoso e indolente.

Valdelomar nos dá su obra preñada de resonancias aldeanas y bucólicas, que nos traen la visión de la "IMAGEN PRIMIGENIA" que dijera Burckhardt. Es la descripción y el retrato de aquella su aldehuela de San Andrés:

"Por las calles no transitan al medio día las personas y nada turba la paz de equella aldea, cuyos habitantes no son más numerosos que los dátiles de sus veinte palmeras. Iglesia ni Cura habían, en mi tiempo, las gentes de San Andrés. Los Domingos, al clarear el alba, iban al puerto, con los jumentos cargados de corvinas frescas y luego en la capilla, cumplían con Dios. Buenas gentes, de dulces rostros, tranquilo mirar, morigeradas y sencillas, indios de la más pura cepa, descendientes remotos y ciertos de los hijos del Sol, cruzaban a pie todos los caminos; como en la Edad Feliz del Inca, atravesaban los caminos; como en la Edad Feliz del Inca, atravesaban en caravana inmensa la costa para llegår al templo y oráculo del buen Pachacamac, con la ofrenda en la alforja, la pregunta en la memoria y la Fé en el sen cillo espíritu".

La visión, el retrato de lo íntimo nuestro, de lo nativo, de lo criollo, a través de lo ecuménico de su intento. Este es el mérito de Valdelomar, este su tributo.

Su posición Colónida, anti-academicista, iconoclasta si se quiere de falsas figuras; representa el primer intento en nuestra literatura ,por la liberación de aquel anquilosamiento de retórica retorcida en que se hallaba.

Venerando respetuosamente a Prada - cuya contribución constituye el primer aporte formal de renovación - y reponiendo la figura de José María Eguren, injustamente olvidado y relegado entonces, el grupo Colónida, que dirigía y presidía Valdelomar, implanta así y testifica, el espíritu renovador que significaba la presencia del movimiento simbo lista en la literatura de nuestro medio. 
"Fl de Valdelomar - ha escrito el pofesor Xammar - fué un ademán de sembrador". Es más, podemos agregar: Valdelomar en su vida, en su obra y en su gesio, fué íntegramente un sembrador.

Trajo a la literatura de nuestra patria los elementos renovadores $y$ universales de la literatura coetánea, y los sembró con su obra, con su vida y con su gesto.

Con cuánta verdad intuía Vallejo, este aporte, esta su presencia ulterior en nuestra literatura, cuando escribía en "La Prensa" el 4 de noviembre del año de su muerte:

"Por eso volverás, hermano, grande amigo. Así lo siento y lo quiero en este crepúsculo de primavera con cuya tinta rosada y triste escribo ahora".

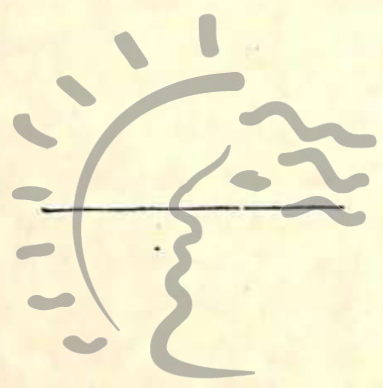

\section{Biblioteca de Letras "Jorge Puccinelli Converso"}

